\title{
INSTITUCIONALIZAÇÃO DO SISTEMA INTERAMERICANO DE COMBATE ÀS DROGAS: INICIATIVAS E PROGRESSOS
}

\author{
Matheus Bernardes Rachadel * \\ Jaime Alonso Caravaca-Morera * \\ Clarissa Franzoi Dri ${ }^{* * * *}$
}

\section{INTRODUÇÃ̃o}

O uso e abuso de drogas não é um fenômeno recente. O mundo já tem percorrido um longo caminho entre erros e acertos nesse assunto. Em ritmo crescente, após a extensão do mundo das drogas das elites para as camadas com maior vulnerabilidade econômica, com a invenção do crack, o problema se mostra cada vez mais enraizado na sociedade latino-americana.

O Brasil e outros países esquivaram-se durante décadas do fenômeno em que as drogas se transformavam, como se fosse um problema alheio, principalmente de países desenvolvidos onde derivados do ópio e a própria cocaína eram consumidos em grande volume. Assim, a questão das drogas sempre teve uma dimensão internacional inerente,

\footnotetext{
* Possui graduação em Relações Internacionais pela Universidade Federal de Santa Catarina (UFSC). Atualmente é bolsista no Oirã Grupo de Pesquisa e Extensão em Cooperação Regional da Universidade Federal de Santa Catarina. Tem experiência na área de Ciência Política, com ênfase em Relações Internacionais, Bilaterais e Multilaterais; Cooperação Regional; Saúde Internacional. Contato: matheusbr@ig.com.br

** Enfermeiro da Universidade da Costa Rica (UCR). Doutorando do Programa de Pós Graduação em Enfermagem PEN/UFSC. Mestre pelo PEN/UFSC. Especialista em Saúde Internacional pelo Centre of Addictions and Mental Health-Canadá (CICAD/CAMH). Membro do Grupo de Estudos de História do Conhecimento da Enfermagem e Saúde. Florianópolis, SC, Brasil. Contato: jacamorera@ hotmail.com

*** Doutora em Ciência Política do Instituto de Estudos Políticos da Universidade de Bordeaux. Professora Adjunta de Relações Internacionais da UFSC. Coordenadora do Oirã - Grupo de Pesquisa e Extensão em Cooperação Regional. Contato: clarissa.dri@ufsc.br
}

Em Tese, Florianópolis, v. 10, n. 2, jul./dez., 2013. ISSN: 1806-5023 
porém foi somente a partir da década de 1980 que os países latino-americanos pareceram despertar para o quão evidente era a necessidade de cooperação nessa área.

Antes disso, o presidente dos Estados Unidos (EUA) entre 1969 e 1974, Richard Nixon, declarou em 1971 a primeira "guerra às drogas" da história, tendo por alvo principal primeiro a produção e o tráfico de opiáceos e, na sequência, da cocaína. $O$ uso da cannabis não foi enfatizado, já que nessa época não era ainda considerado alarmante.

Os EUA passaram então a securitizar, ou trazer para a esfera de problemas de segurança de Estado, a questão da droga nas Américas, influenciados em grande parte pelos avanços dos países andinos, como grandes produtores da folha de coca e seus derivados, e pelo fato de o comércio de cocaína no hemisfério gradualmente ter se transformado em um negócio multibilionário e altamente organizado; em pouco tempo, a partir da demanda crescente, esse mercado passou da produção precária para um negócio multinacional totalmente integrado (SILVA, 2013).

Contudo, as primeiras atuações de monta de países latino-americanos no cenário internacional em relação às drogas só foram acontecer a partir do momento em que os países andinos, principalmente, sentiram suas economias ameaçadas. Essas ações tinham o intuito de igualar a repressão sofrida pelas drogas sintéticas (produzidas na época em países desenvolvidos) e pelas drogas de origem vegetal, tendo em vista que estas últimas haviam se tornado extremamente importantes para a economia local, além de sua importância cultural, que era reafirmada constantemente nos fóruns internacionais. "Ainda que a motivação dessas primeiras faíscas tenha sido sobretudo uma retaliação, foi uma evolução significativa na atuação dos países da região nos foros multilaterais" (SILVA, 2013, p. 129).

Enquanto isso, no Brasil começava a haver uma movimentação no sentido da criação de um arcabouço institucional e jurídico. A partir dos anos de 1970, com a chegada mais forte do fenômeno das drogas ao sul do continente, alguns passos foram dados para a formalização do combate a esse fenômeno.

Em 1976, pouco depois de Nixon declarar a primeira guerra às drogas, aprovou-se a Lei 6.368/76 dispondo sobre medidas de prevenção e repressão ao tráfico ilícito e uso indevido de substâncias entorpecentes ou que determinem dependência física ou 
psíquica. Um alarme começava a soar cada vez mais forte em toda a América, nos anos 1980, foi perceptível um incremento do uso de drogas; no entanto, a guerra às drogas já declarada não vinha surtindo grandes efeitos (FERREIRA NETO, 2012).

Neste cenário de imposições, paradoxos e regulamentações, e considerando o debate acerca dos temas do uso e abuso de drogas, assim como a sua importância para o setor da cooperação internacional e da saúde, o presente artigo tem por objetivo analisar a criação e consolidação da Comissão Interamericana para o Controle do Abuso de Drogas da Organização dos Estados Americanos (CICAD/OEA) como fórum hemisférico para o fenómeno das drogas.

O trabalho realiza uma articulação lógica de olhares, elementos e conceitos defendidos por diferentes autores, com o intuito de retratar o estado da arte com relação à temática da institucionalização do sistema interamericano de combate às drogas e sintetizar racionalmente as referências escolhidas para continuar o processo reflexivo e o debate dentro e fora das nossas fronteiras.

Para tanto, a primeira parte traça uma retrospectiva histórica das razões que levaram à criação da CICAD como iniciativa agregadora no surgimento de um arcabouço institucional e legal de tratamento do tema das drogas nas Américas. A segunda parte aborda o processo de consolidação da CICAD como instituição central nesse regime, especialmente focada em ultrapassar métodos tradicionais de repressão à oferta de drogas para elaborar incentivos de redução da demanda.

Segundo a própria CICAD (2010) a redução da demanda é um componente prioritário para garantir uma abordagem abrangente e equilibrada para o problema mundial das drogas, uma vez que o abuso de drogas é um problema social e de saúde que requer uma abordagem multissectorial e multidisciplinar. A redução da demanda inclui como elementos essenciais e universais: prevenção, intervenção precoce, tratamento, reabilitação e serviços de apoio relacionados a recuperação, com o objetivo de promover a saúde e o bem-estar social dos indivíduos, famílias e comunidades, e reduzindo as consequências adversas do uso de drogas. 


\section{AS ORIGENS DE UM REGIME REGIONAL DE COMBATE ÀS DROGAS}

A amplitude transnacional dos problemas gerados pelo tráfico e consumo de drogas confere a essa guerra um caráter difuso, ao mesmo tempo em que intensifica o controle social, identificando as drogas como a encarnação do mal. Entre os anos de 1960 e 1980 essa situação já havia se agravado em muito, tanto pelo enorme incremento na oferta e demanda de drogas como pela falta de iniciativa dos Estados americanos. Foi somente a partir do segundo mandato do presidente Reagan (1981-1989) nos EUA que se iniciou um maior investimento no combate e um processo de total securitização do fenômeno das drogas. Várias novas frentes de batalha foram iniciadas, porém a grande maioria centrada na securitização do problema, tratando da questão do narcotráfico e da oferta, deixando a redução da demanda em segundo plano (SILVA, 2013).

A guerra às drogas trouxe consigo inúmeros desafios aos países da América Latina e em específico aos produtores. A região sofreu/sofre mais contundentemente as consequências econômicas e sociais das políticas proibicionistas. Essas consequências foram advindas mormente dos questionamentos dos EUA em relação ao engajamento e eficiência das ações por parte de seus "parceiros" (FRAGA, 2007, p. 87). Esses questionamentos, porém, não eram infundados. Nessa guerra, tais países lutavam divididos entre o interno e o externo, a fim de atingir um equilíbrio extremamente delicado. Por um lado, deveriam colaborar com a erradicação de um setor econômico muito lucrativo para suas economias e, por outro, manter a harmonia interna sem criar uma crise econômica e social.

Assim, os governos se viram obrigados a tomar grande cuidado quanto aos movimentos: um passo atrás nas ações implementadas com base na guerra às drogas implicaria em sanções internacionais, má reputação e retaliações, e um passo adiante mal planejado levaria a conflitos com camponeses, cooperativas, guerrilhas e narcotraficantes.

Dessa forma, acabavam por prestar uma cooperação predominantemente de fachada. No Peru, por exemplo, surgiu em meados da década de 1960 o Sendero Luminoso, movimento de cunho ideológico que, aliado aos produtores de coca, passou a

Em Tese, Florianópolis, v. 10, n. 2, jul./dez., 2013. ISSN: 1806-5023 
denunciar a erradicação de cultivos como um ataque imperialista norte-americano contra os interesses campesinos.

Por outra parte, na Bolívia, as concessões à guerra às drogas gerariam protestos cada vez mais organizados do setor rural, pois a continuidade dos programas de erradicação atingia, de maneira incisiva, muitas plantações que não eram destinadas ao tráfico. Assim, a consideração da folha de coca como substância psicoativa ilegal, desde 1961, confronta-se com os direitos humanos fundamentais de etnias andinas quanto ao plantio e ao consumo da planta (SILVA, 2013, p. 156).

Dos 42 grupos terroristas apontados pela lista de 2008 da Foreign Terrorist Organization, quatro eram latino-americanos, e todos envolvidos de alguma forma com a questão das drogas, entre eles as Forças Armadas Revolucionárias da Colômbia (FARC) e o Sendero Luminoso (PAGLIARI, 2009, p. 175).

Nesse processo de ações unilaterais, principalmente norte americanas, destinaram-se centenas de milhões de dólares em ações, a fim de implementar investidas contra a produção e tráfico. Contudo, a guerra às drogas e o proibicionismo como políticas não só não conseguiu atingir os seus objetivos declarados de reduzir a oferta e demanda de drogas, como também contribuiu para altos níveis de crimes, corrupção, violência, encarceramento e um mercado clandestino vasto e destrutivo.

Ortiz (2009, p. 23) destaca oito pontos para todas as tentativas de guerra às drogas não terem dado certo: i) a demanda por drogas é inelástica por causa da condição de dependência e consumo; ii) o preço da droga é acima do custo marginal, porque a atividade exige riscos; iii) o setor da droga proporciona extraordinários lucros; iv) o preço da droga aumenta com a repressão às drogas; v) o setor se reproduz conforme a repressão de abastecimento; vi) a abertura da economia leva a uma maior especialização em atividades ilegais de drogas; vii) a repressão às drogas diminui a taxa de crescimento econômico, tanto a curto prazo quanto a longo prazo; viii) em longo prazo, um maior grau de repressão leva a impostos mais elevados e uma taxa de crescimento de longo prazo menor.

Consequentemente, Passos e Souza (2011) acreditam que a guerra às drogas se tornou ao mesmo tempo um exercício de controle social e uma estratégia para a

Em Tese, Florianópolis, v. 10, n. 2, jul./dez., 2013. ISSN: 1806-5023 
ampliação da economia neoliberal a partir do exercício do poder e da violência. A economia neoliberal se fortaleceu através da intensificação de uma economia bélica, já que a lógica de guerra às drogas e a lógica de consumo, segundo os autores, não são lógicas opostas, elas se alimentam e se fortalecem mutuamente.

Porém, paralelamente às ações unilaterais e às pressões intrusivas sobre governos estrangeiros, a administração Reagan introduziu o tema na agenda de cooperação hemisférica, sendo que, por sua iniciativa, concretizou-se em 1986 a Primeira Conferência Interamericana sobre Drogas (SILVA, 2013).

Para entrar mais especificamente nos caminhos que levaram a conferência, é preciso analisar mais profundamente a interação entre as Américas e as drogas, uma relação com muitas nuances e complexidades. Durante décadas, os governos de alguns países produtores e de trânsito na América Latina consideraram a questão das drogas ilegais como um problema, sobretudo norte-americano. Pois se o narcotráfico representou uma força econômica poderosa nos países produtores, é um negócio de ainda maiores proporções nos países consumidores (FERREIRA NETO, 2012, p. 234).

Porém quando se começou também a ocorrer um maior consumo nos próprios países latinos, principalmente das drogas mais baratas, a maconha e variações de custo reduzido como o crack, gerando demandas antes não verificadas na saúde pública destes países, é chamada fortemente a atenção dos formuladores de políticas públicas.

Desta forma, se abre uma janela para o enfrentamento do fenômeno das drogas na América Latina, em 1973 e foi criado o Acordo Sul-Americano sobre Entorpecentes e Psicotrópicos (ASEP), em Buenos Aires, com a participação de dez países da região. Entretanto, a iniciativa demorou cerca de oito anos para começar a funcionar após a assinatura do acordo, o que reflete a falta de interesse dos Estados membros. O ASEP não teria longa vida e nem grande impacto, porém traria alguns precedentes para a CICAD e foi importante para despertar a cooperação no tema (SILVA, 2013, p. 204).

Já em meados dos anos de 1980 surgiu uma nova iniciativa sobre a temática no continente. Como um foro de caráter técnico e policial surgiu a Conferência Internacional para o Combate às Drogas (International Drug Enforcement Conference IDEC), criada em 1983 por meio de uma combinação inicial de esforços dos EUA e da

Em Tese, Florianópolis, v. 10, n. 2, jul./dez., 2013. ISSN: 1806-5023 
Guarda Nacional do Panamá, dado que esse país representava à época a principal zona de trânsito da droga do sul para o norte). Teve como papel a colaboração no compartilhamento de experiência e cooperação técnica, onde o Brasil teve um importante papel através da Polícia Federal (SILVA, 2013).

$\mathrm{Na}$ OEA, o tema das drogas começou a aparecer mais fortemente a partir do desejo norte-americano de unir a guerra às drogas com uma atuação mais multilateral. Esse desejo tem ligação direta ao ônus do país ao ser o maior controlador dos países latino-americanos quanto ao engajamento na guerra às drogas. A visão multilateral no âmbito da OEA retiraria um pouco da carga do Estado norte americano como inquisidor isolado. Levava-se em consideração, principalmente, que a cooperação em um foro multilateral poderia vir a compilar dados e estatísticas fidedignos demonstrando o agravamento do problema em todo o hemisfério, colaborando dessa forma com a tarefa de convencer os países vizinhos de que seria de seu interesse combatê-lo.

Nessa época também podemos destacar uma maior predisposição política na América Latina para a cooperação e o tratamento do tema. Em diversos países, incluindo o Brasil, o processo vivido era de transição de governos desenvolvimentistas para o paradigma de Estado neoliberal. Segundo Cervo (2007), começou a sair de cena o Estado extremamente interventor, entrando o Estado logístico. Os Estados passaram a se preocupar mais com suas políticas externas e passaram confiar e acreditar mais na necessidade e eficiência das instituições internacionais e da cooperação. Formando uma visão institucionalista liberal, com Estados mais abertos e dispostos a cooperar para a formação de regimes internacionais para o tratamento de problemas em conjunto.

É claro que a cooperação no fenômeno das drogas como vimos até agora se faz num contexto de Estados independentes movidos pelos seus próprios interesses e não exatamente pela devoção ao bem comum. Porém, a ideia da criação de um regime internacional para o tratamento desse problema a partir das já cimentadas bases da OEA ajudou a criar uma expectativa de maior congruência entre a atuação de todos os atores envolvidos, principalmente dos Estados participantes.

Olhando através da lente do institucionalismo liberal apresentado por Robert Keohane (2005), isso se deve pelo fato dos regimes criarem as condições para ordenar

Em Tese, Florianópolis, v. 10, n. 2, jul./dez., 2013. ISSN: 1806-5023 


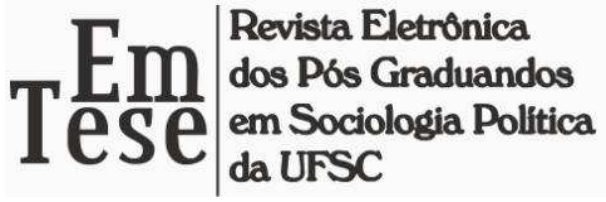

negociações multilaterais, legitimando e deslegitimando diferentes tipos de ação estatal e facilitando ligações entre questões dentro de regimes e entre os próprios regimes. No entanto as fraquezas das organizações internacionais e os problemas de obrigatoriedade do direito internacional algumas vezes despistam os observadores e os levam a pensar que os regimes internacionais são insignificantes e que podem ser ignorados por completo.

Contudo, ainda que a integração global seja delicada, os regimes internacionais apresentam importantes efeitos sobre as relações de interdependência que envolvem alguns poucos ou muitos países em um problema específico. Concomitantemente, os regimes incrementam a simetria e melhoram a qualidade da informação que os governos recebem. Por estabelecerem padrões legitimados de comportamento para os Estados seguirem e por fornecerem modos de controlar o comprometimento deles, os regimes criam as bases para a execução descentralizada fundada no princípio da reciprocidade (KEOHANE, 2005).

Segundo Young (2000), os regimes são fenômenos já inerentes aos sistemas políticos. O autor coloca uma perspectiva que questiona a tese realista de que os Estados visariam à segurança e à sobrevivência como únicos objetivos e sustenta que os regimes são eficazes na medida em que conseguem focar a atenção dos Estados e agentes para cooperação em áreas específicas da política internacional, como as ações para tratar o fenômeno das drogas. Em um mundo de Estados soberanos, a função básica dos regimes deve ser coordenar o comportamento estatal para realizar os resultados desejados em determinadas questões. Essa coordenação, por sua vez, pode ser atraente em diversas circunstâncias, tais como as que aparecem quando os atores não conseguem realizar resultados desejados baseados em ações individuais.

A questão das drogas inseria-se em grande medida nessa nova agenda de cooperação na América, onde se destacam a criação de um sistema interamericano de combate às drogas e principalmente a revitalização da OEA a partir dos anos 1980 como foro de debate e de cooperação. Isso se deveu principalmente às mudanças de paradigma político-burocrático dos Estados latino-americanos. Instaurou-se uma coincidência no tocante às vantagens da democracia representativa e das reformas

Em Tese, Florianópolis, v. 10, n. 2, jul./dez., 2013. ISSN: 1806-5023 
econômicas de mercado, maior disposição em cooperar multilateralmente e adensamento da agenda hemisférica com o surgimento de novos temas: comércio, investimentos, migrações, meio ambiente, saúde pública, entre outros.

Porém, apesar de eleita, com forte influência norte-americana, como a instituição que faria acontecer a cooperação para o fenômeno das drogas na América, a OEA viu esse diálogo inicialmente dificultado pela inexistência de mecanismos e instituições formalizadas para alçar um sistema interamericano de combate às drogas (HORWITZ, 2010). A temática, contudo, começou a aparecer na maioria dos foros da instituição, através da insistência dos EUA, que buscavam outro viés para o tratamento do problema, já que a guerra às drogas com ações unilaterais havia surtido pouco efeito, além do interesse de países de trânsito e produtores que tinham as pretensões de ampliar e fortalecer o diálogo norte-sul para gerenciar suas perdas (SILVA, 2013).

Consequentemente, foram paulatinamente criadas iniciativas isoladas de discussão e proposição para o tratamento do tema. Em 1982 um grupo de trabalho da OEA com a atribuição de examinar possíveis ações para conter o agravamento do problema das drogas foi criado. O Brasil foi apenas observador do grupo, integrado pelos EUA, Argentina, Bolívia, Colômbia e Peru. A partir de 1984, tomou força na OEA a articulação para a formação do sistema interamericano de combate às drogas. Como fruto da atmosfera favorável já indicada, os chefes de Estado de países sulamericanos assinaram em 1984 a "Declaração de Quito contra o Tráfico de Drogas", que se transformou na primeira declaração nessa linha (HORWITZ, 2010).

Foi assim que, durante a $14^{\mathrm{a}}$ Assembleia Geral da OEA, em Brasília, em novembro de 1984, foram examinadas três propostas referentes ao combate ao narcotráfico nas Américas. A primeira fazia referência à convocação de uma conferência especializada interamericana sobre a matéria, apresentada pelo grupo de trabalho da OEA. A segunda tratava sobre a negociação de uma convenção interamericana sobre drogas, e a terceira mencionava a criação de um fundo de assistência para a erradicação e substituição de cultivos nos países produtores da região.

Apesar da grande aceitação por parte dos Estados das propostas supracitadas, nenhuma foi posta em prática prontamente, devido principalmente a restrições

Em Tese, Florianópolis, v. 10, n. 2, jul./dez., 2013. ISSN: 1806-5023 
orçamentárias. Contudo, com o apoio persistente dos EUA, começou-se a buscar o país sede para a acordada convenção interamericana sobre drogas. Inicialmente foram sondados Brasil e Argentina, que declinaram do convite, sendo que o governo brasileiro não pretendia assumir um protagonismo na esfera do combate às drogas.

Segundo a área política do Itamaraty, não convinha dar-se "realce imerecido" aos aspectos internacionais das drogas no território nacional, "tendo em vista não ser o país um grande produtor ou exportador na região" (SILVA, 2013, p. 214). Todavia, com a entrada de José Sarney na presidência da República, em 1985, após um longo período de governos totalitários, novos tópicos e uma grande lista de afazeres entraram na pauta do incipiente Estado democrático. Era essencial incentivar o estreitamento de laços na região e iniciar a cooperação tão fortemente demandada em nível internacional em temas centrais para o continente, entre eles as drogas.

Mesmo o Brasil ainda não se mostrando como um forte líder na região, seu desejo era participar mais intensamente no meio internacional à época. Foi nesse contexto que, em meados de 1985, o Brasil reconsiderou a possibilidade de o país vir a sediar a Conferência Especializada. A ideia foi aprovada pelo Itamaraty, que não tardou a perceber as vantagens de uma maior exposição do Brasil, ao sediar o evento e contribuir para a inclusão definitiva do tema das drogas na pauta da OEA.

A Conferência Especializada Interamericana sobre o Tráfico de Entorpecentes foi realizada então no Rio de Janeiro, em abril de 1986. Na pauta estava a proposta de criação de um foro com a atribuição de promover a cooperação interamericana na matéria. O documento adotado ao final do encontro foi intitulado "Programa Interamericano de Ação contra a Produção e o Tráfico Ilícito de Entorpecentes e Substâncias Psicotrópicas" (conhecido como "Programa do Rio"). O documento reforçava o consenso regional de que o narcotráfico ameaçava o desenvolvimento socioeconômico na região e as instituições democráticas, demandando uma abordagem equilibrada e integral que focalizasse os diferentes aspectos envolvidos na questão (redução da demanda, prevenção do uso indevido, tratamento de dependentes e combate ao tráfico ilícito).

Em Tese, Florianópolis, v. 10, n. 2, jul./dez., 2013. ISSN: 1806-5023 
Mas o maior avanço da conferência foi a recomendação do estabelecimento de uma comissão interamericana competente. Essa demanda posteriormente se materializaria na Comissão Interamericana para o Controle do Abuso de Drogas, tendo o Programa do Rio como escopo para seu trabalho.

\section{A CICAD COMO FORO DE DEBATE PARA O FENÔMENO DAS DROGAS}

Os objetivos iniciais do novo órgão foram principalmente no sentido de ampliar e fortalecer a capacidade dos Estados membros de reduzir a demanda e prevenir o abuso de drogas, combater eficazmente a produção e tráfico ilícitos bem como promover uma resposta interamericana apropriada mediante o aumento das atividades regionais em matéria de pesquisa, intercâmbio de informações, treinamento e cooperação técnica. Horwitz (2010) destaca que alguns esforços como o Programa Interamericano de Ação do Rio de Janeiro em 1986 e a criação de um mecanismo institucional interestadual, a CICAD, montaram o palco para um regime antidrogas embrionário. Contudo, a CICAD devia enquadrar suas ações dentro dos parâmetros estabelecidos pelas convenções internacionais para o controle de drogas já existentes.

Irving Tragen (2012), primeiro Secretário Executivo da instituição, coloca que inicialmente a CICAD contou com onze membros apenas, o que posteriormente foi ampliado até a totalidade dos atuais 35 membros da OEA. Os membros iniciais foram: EUA, Bolívia, Colômbia, México e Peru, Venezuela, Bahamas, Guatemala, Panamá, Argentina e o Brasil. O Brasil ingressou, sobretudo, como anfitrião na Conferência do Rio e a Argentina na qualidade de Secretaria do ASEP, que seguia em vigor, em vista do interesse de seu governo pelo tema. Em março de 1987, a Comissão reuniu-se pela primeira vez. O Secretário Executivo esteve à frente, nos primeiros tempos, de uma equipe diminuta de treze funcionários, dispondo de orçamento relativamente modesto. Contudo, em pouco tempo a equipe e os recursos se expandiram consideravelmente. Os demais países membros se revezavam na presidência (anual) do órgão, assumindo funções mais protocolares do que operativas. Ao país presidente, na pessoa do

Em Tese, Florianópolis, v. 10, n. 2, jul./dez., 2013. ISSN: 1806-5023 
representante do órgão nacional acreditado como coordenador (com mandato de um ano), caberia conduzir as duas sessões plenárias semestrais realizadas durante aquele período e sediar uma delas, além de acompanhar a elaboração e colocação em prática do programa de trabalho anual. Quanto à função de Secretário Executivo, cargo muito mais pragmático e influente dentro da instituição, cabe dizer que em todos os mandatos o lugar foi ocupado por norte-americanos.

A CICAD foi um grande passo à frente para os países do continente no combate ao fenômeno das drogas. Com esse novo sistema interamericano de combate às drogas que se estabelecia, seria possível coordenar de forma mais eficiente as ações desenvolvidas por todos os países, além da criação de novos programas e políticas em conjunto através da instituição. Além disso, todos os Estados membros da OEA passariam a contar com um foro político, técnico e de colaboração acadêmica bem estruturado e dotado de recursos humanos e financeiros adequados (ROSENBERG, 2001, p. 88), em cujo âmbito poderiam propor iniciativas de cooperação em todos os níveis de combate às drogas, desde a redução da demanda abrangendo o indivíduo até o narcotráfico e a lavagem de dinheiro em escala global.

Nos primórdios da instituição, foi acordado que a CICAD auxiliaria a identificar os principais problemas e proporia medidas para seu enfrentamento. A assistência seria fornecida com base nas solicitações dos Estados membros, e de forma alguma imposta. Além disso, o principal objetivo da cooperação regional seria apoiar e coordenar, por meio de programas a nível continental, os esforços antidrogas dos países membros, apoiando-se prioritariamente em ações de cooperação bilateral e multilateral entre os países. Os primeiros movimentos foram no sentido de estabelecer as bases do sistema interamericano, incluindo desenvolvimento jurídico, educação preventiva contra as drogas, mobilização comunitária, desenvolvimento de um sistema regional de informação sobre drogas e de estatísticas padronizadas.

Sobre o financiamento da instituição, o Plano de Ação do Rio (OEA, 1987), inicialmente, estipulou que os recursos oriundos do fundo ordinário da OEA seriam destinados, basicamente, à manutenção da maquinaria administrativa da Secretaria Executiva. O financiamento de projetos teria de vir de fontes orçamentárias externas. A

Em Tese, Florianópolis, v. 10, n. 2, jul./dez., 2013. ISSN: 1806-5023 
partir desse modelo, ficou com os contribuintes a prerrogativa de selecionar os projetos específicos a serem patrocinados com suas doações, o que deu, na prática, certa influência aos atores externos sobre as atividades a serem desenvolvidas pela CICAD. Foi preciso passar a realizar prestação de contas dos fundos de contribuições voluntárias. Contudo, esse modelo de financiamento corresponde a um modelo de cooperação técnica e financeira que não implica que a instituição ou os países membros fiquem completamente à mercê dos colaboradores externos. Os projetos, sua formulação e implementação continuam sendo responsabilidade da CICAD, e aos Estados membros cabe também a proposição de iniciativas. Os financiadores têm a possibilidade de fazer sugestões para a adequação do orçamento destinado (WRIGHT et al., 2004).

Nesse ponto é perceptível que falta um maior esforço por parte dos Estados membros em dedicar uma parcela maior de contribuição à instituição. Tal empenho tornaria a instituição mais autônoma no sentido de ter todas as suas ações provenientes de decisões internas tomadas a partir de critérios estabelecidos exclusivamente pela CICAD e seus membros. Apesar disso, é preciso levar em conta que, mesmo em seus primeiros anos, a lista de ações da CICAD foi bastante expressiva, o que demonstra o interesse inicial por parte dos membros e também de entes externos, contribuintes ou não, em cooperar e contribuir com a instituição.

Entre as primeiras conquistas da instituição, destaca-se a criação de um banco de dados e de um centro de documentação, produção de ampla gama de informações e publicações, realização de oficinas na área de redução da demanda e apoio às ações comunitárias e privadas antidrogas. No âmbito do desenvolvimento jurídico, lançaramse programas de ação nas áreas de confisco de bens oriundos do narcotráfico, controle de precursores químicos, combate à lavagem de dinheiro, cooperação judiciária e extradição (SILVA, 2013, p. 222).

No ano de 1989, estipulou-se que a comissão passaria a apresentar anualmente à OEA um relatório sobre a situação do problema das drogas no hemisfério. Esse documento englobaria todas as ações, seus avanços e retrocessos, funcionando como um mapa sináptico da instituição, mostrando seus pontos críticos, aquilo que deveria ser mais trabalhado, o que deveria ser mantido e o que poderia ser implementado de novo,

Em Tese, Florianópolis, v. 10, n. 2, jul./dez., 2013. ISSN: 1806-5023 
colaborando para que os Estados membros e outros parceiros possam perceber em que patamar se encontra a eficiência da cooperação e também para que a própria OEA possa verificar quais pontos deve estimular nesse sentido (CICAD, 2011).

Em 1989, também se iniciaram os esforços de capacitação na área de precursores químicos, componentes utilizados para a preparação de drogas, mas que em si não são substâncias ilegais. Foi criado um grupo de peritos sobre o tema, fornecendo assistência técnica para o fortalecimento dos sistemas nacionais de controle (CICAD, 2011). Foi nessa área que a CICAD elaborou, a partir de uma proposta norte-americana, seu primeiro Regulamento-Modelo, já em 1990, na esfera de precursores químicos. Em 1992, foi lançado o Regulamento-Modelo sobre Lavagem de Infracções relacionadas com o Tráfico Ilícito de Drogas e Crimes relacionados, e em 1998 foi divulgado o Regulamento-Modelo para o Controle do Movimento Internacional de Armas de Fogo.

Nesse sentido, a elaboração de regulamentos-modelo e manuais se tornaria para a CICAD a principal forma de contribuir com as políticas públicas dos países membros. Esses manuais, pareceres, relatórios, avaliações e modelos tornaram-se instrumentos essenciais para a cooperação não só entre Estado e organização, mas também entre Estados. Dessa forma, a padronização das políticas sobre drogas implementadas vem contribuir na facilitação do diálogo entre governos, pois acabam se formando extensões de programas similares em toda a América, o que amplia muito os pontos sensíveis a alguma forma de intercâmbio de informação e colaboração técnica.

Durante os primeiros anos, as discussões no âmbito da CICAD foram bem diversificadas, passando por pontos polêmicos e temas controversos, trazidos à tona principalmente por países latino-americanos, sendo que as plenárias da CICAD costumavam ensejar alguns debates politizados sobre temas afetos à problemática das drogas, tais como o processo de certificação norte-americano. Processo pelo qual o Congresso norte americano passou a exigir do Departamento de Estado uma avaliação anual dos países, com base no desempenho de cada um no combate às drogas. Cabendo ao Presidente, com base nas recomendações do Departamento de Estado, enviar anualmente ao Congresso a lista dos países certificados integralmente, certificados com base nos "interesses vitais" norte-americanos e descertificados.

Em Tese, Florianópolis, v. 10, n. 2, jul./dez., 2013. ISSN: 1806-5023 
A certificação, integral ou com base em interesses vitais, permitiria a manutenção integral de programas de assistência existentes, ao passo que a descertificação resultaria em sanções, congelamento da assistência e importações, além da denegação de financiamento e voto contrário a pedidos de empréstimos junto a organismos multilaterais de desenvolvimento (SILVA, 2013, p. 224).

As discussões mais acaloradas, com o tempo, deram lugar ao consenso na maioria dos temas tratados pela instituição, não só pela acomodação dos anseios e perspectivas por parte dos Estados, mas também pelas tentativas de evitar qualquer desconforto dentro da organização.

Durante o final dos anos 1980 e início dos anos 1990, a CICAD passou por um processo de consolidação como foro do hemisfério ocidental sobre a temática das drogas, passando de um órgão apenas de pesquisa e coleta de dados com alguns projetos, para uma instituição funcional, pragmática e reconhecida, essa transição se deu pelo grande aumento no número de projetos financiados por membros e não membros, pela conscientização da importância da cooperação dentro da instituição para o enfrentamento do fenômeno das drogas e um exponencial crescimento da importância dada a instituições internacionais ao longo dos anos 1980/1990.

A partir dessa evolução da instituição, em 1990 convocou-se uma reunião ministerial em Ixtapa (México), com o objetivo de reavaliar a situação do problema das drogas no hemisfério, determinar prioridades para uma ação conjunta e aprovar medidas específicas. A Declaração e o Plano de Ação aprovados no encontro fixaram as novas prioridades da CICAD na execução do Programa do Rio, ampliando seu escopo de atuação.

Horwitz (2010, p. 147) coloca que, graças ao apoio dos EUA, um quadro regional foi desenvolvido entre 1990-1991. A Declaração e Programa de Ação de Ixtapa, e o posterior Programa Interamericano de Quito (Equador) de Educação Preventiva Integral para o Abuso de Drogas foram estratégias e programas que tentaram enquadrar o fenômeno das drogas ilegais em sua totalidade, como uma ameaça que exige uma abordagem multilateral. Mais ainda, estas estratégias de segurança comum incluíram um mecanismo de cooperação concreta, a CICAD. É possível salientar que, 
nesse período de consolidação da instituição, o mais importante foi a conquista da inclusão da temática em todas as instâncias da própria OEA.

Entretanto, durante a Primeira Cúpula das Américas em Miami, já em 1994, os EUA novamente tentaram apontar o foco para as questões de segurança ligadas às drogas. Foi sugerida até mesmo uma entidade paralela para tratar de temas de cunho mais "beligerante" do combate ao problema. Sugerido pelo Estado norte-americano, o documento intitulado "Estratégia Hemisférica Antidrogas" priorizava os aspectos de interdição especialmente erradicação de cultivos, controle de fronteiras e extradição de narcotraficantes, que os EUA desejavam há muito tempo ver implementados com maior vigor. Porém, os elementos centrais da estratégia hemisférica definidos na Cúpula de Miami foram objeto de discussão e detalhamento, para amadurecimento das ideias, no âmbito da CICAD entre 1995 e 1996 (PROCÓPIO; VAZ, 1997, p. 111).

Dessa forma, começam a surgir questionamentos sobre o foco que a CICAD iria oferecer para o combate às drogas. Silva (2013) coloca a carência de debate em torno da necessidade de equilíbrio nas atividades da CICAD e propõe uma análise das atividades da Comissão em 1994 que mostra clara priorização dos esforços na esfera de securitização e lavagem de dinheiro: enquanto a redução da demanda contava com um projeto, a redução da oferta contava com nove. Enquanto foram feitos esforços para acabar com colheitas e produção de drogas, a demanda em todo o continente se expandia exponencialmente, sem a devida atenção de base de que necessitava para ser reduzida.

Contudo, esse lapso de falta de amplitude no tratamento do tema dentro da CICAD não se estendeu por um longo período, já que as propostas dos EUA mencionadas não deram frutos. Após a identificação das tendências de extrema securitização, foram tomadas as providencias para a elaboração de um texto alternativo, que priorizava uma visão multidisciplinar do tema.

A proposta tornou-se um documento de trabalho, negociado sob a presidência do Uruguai e adotado em 1996 com o título de "Estratégia Hemisférica Antidrogas". Ela "tornou-se uma referência para a cooperação interamericana no tratamento integral, multidisciplinar e equilibrado, da questão das drogas" (SILVA, 2013. p. 230). Logo na

Em Tese, Florianópolis, v. 10, n. 2, jul./dez., 2013. ISSN: 1806-5023 
sequência, em 1997, foi aprovado o Plano de Ação correspondente que, juntamente com a estratégia, passou a constituir instrumento básico da CICAD. Esse plano singularizou a redução da demanda como um elemento chave e prioritário das políticas sobre o tema e listou uma série de medidas a serem adotadas pelos governos nacionais (SILVA, 2013). A partir desse ponto, a CICAD consolidou o consenso hemisférico quanto à importância de se tratarem os dois aspectos do problema, redução da oferta e da demanda, de forma equilibrada e integrada. Se hoje parece óbvia a constatação de que as duas estratégias devem ser aplicadas simultaneamente, até então era clara a prioridade atribuída à primeira.

A manutenção de um equilíbrio adequado entre atividades de redução da demanda e da oferta depende das características dos problemas em cada Estado. Com o estabelecimento do Plano de Ação e dos Programas Interamericanos de Quito e Ixtapa, foram então delineados os quatro novos programas de ação prioritários da CICAD, sendo eles: redução da demanda e da oferta, desenvolvimento jurídico, fortalecimento das Comissões Nacionais e criação de um Sistema Interamericano sobre Drogas (CICAD, 2010).

Com essas novas ferramentas e atribuições, a Comissão ampliou seus propósitos originais, passou a englobar o problema das drogas sintéticas e crimes derivados do fenômeno das drogas como tráfico de armas de fogo, violência juvenil, gangues relacionadas às drogas. Para a CICAD, o aumento da violência e a necessidade do uso da força deixam transparecer apenas a superfície do problema. A violência relacionada com o tráfico de drogas está ligada diretamente com o aumento dos níveis de uso de drogas em todo o hemisfério. Enquanto progresso tem sido feito nos últimos anos em interromper o fluxo de produção de drogas, mais precisaria ser feito para coibir o uso de drogas, o que representa um aumento do custo social e econômico de nossas sociedades (CICAD, 2010).

Além desses pontos, outras faces são encaradas no combate: cooperação marítima, segurança portuária, polícia comunitária, temas jurídicos e econômicos e o fomento de pequenas e microempresas para desenvolvimento alternativo sustentável. Tal expansão refletiu a crescente conscientização, nos Estados membros, da estreita 
conexão entre os problemas de abuso e tráfico de drogas e uma série de questões socioeconômicas e delitivas graves que começavam a vir à tona, concordando-se que não deviam ser tratadas de forma isolada no continente. Finalmente, a CICAD passou também a fornecer as bases para o desenvolvimento de um quadro regional para a divulgação de informações. Durante os anos 2000 foram criados bancos de dados, como a Rede Interamericana de Telecomunicações, Rede de Controle de Drogas e o Sistema Interamericano de Dados Uniformes sobre Consumo de Drogas (SIDUC). Esses mecanismos fornecem aos membros da OEA um diagnóstico mais preciso e uniforme de informações sobre a verdadeira natureza e extensão do uso ilegal, tráfico e ações de repressão e educação sobre drogas.

A Estratégia Hemisférica de Drogas, e não mais “antidrogas”, foi atualizada em 2010. Esta foi aprovada em junho pela Assembleia Geral da OEA em sua quadragésima sessão regular em Lima, no Peru. Já em maio de 2011, a CICAD aprovou o Plano de ação 2011-2015 para a nova Estratégia Hemisférica de Drogas em Paramaribo/Suriname (WRIGHT et al., 2012, p. 15). A nova estratégia e plano de ação vieram acompanhar as mudanças ocorridas na temática das drogas. Embora sem trazer mudanças de monta, introduziu alguns conceitos avançados de grande interesse para os países latinoamericanos. A nova estratégia incluiu uma maior atenção ao ser humano na aplicação das políticas sobre drogas. Destacou a pobreza e a marginalização como vias de entrada para o tráfico de drogas, e as mudanças sociais necessárias para mudar esse cenário. Agregou também questões de gênero, além de incentivar ainda mais a comunidade científica, classe política e sociedade civil na participação para a formulação de políticas.

Um dos pontos de maior relevância na nova estratégia hemisférica para a formulação de um novo paradigma para o tratamento do fenômeno das drogas é o fato de que esta reconheceu a dependência de drogas como uma doença crônica com determinantes biológicos, psicológicos e sociais, a ser tratada como um elemento central nas políticas públicas de saúde (INSULZA, 2010). Esta aproximação integrada, com uma forma mais humana de compreender o fenômeno, tem facilitado o desenho de políticas nacionais e internacionais e o compartilhamento de experiências para reduzir o 
fornecimento e o consumo de drogas nas Américas. A CICAD coloca a estratégia e o plano de ação como uma abordagem abrangente para enfrentar os desafios interligados de tráfico e dependência de drogas, sendo fundamental que os países das Américas deem grande ênfase à causa/raiz do problema: o consumo de drogas.

É possível perceber que, a partir desses novos arcabouços, a CICAD espera que a redução da demanda seja um motor para o combate do problema das drogas. Além de incentivar essa abordagem, para que haja um alinhamento com as políticas e ações de cooperação da própria instituição, ela lista na Estratégia Hemisférica de 2010 e no Plano de Ação 2011-2015 uma gama de diretrizes que os países devem seguir para que tanto as suas políticas públicas como as ações em conjunto, de redução da demanda, aconteçam de forma plena (CICAD, 2012). Essa lista evidencia que a redução da demanda é um componente prioritário para garantir uma abordagem abrangente e equilibrada para o problema mundial das drogas, uma vez que o abuso de drogas é um problema social e de saúde que requer uma abordagem multissetorial e multidisciplinar. Segundo a CICAD (2010), o combate deve incluir: serviços de prevenção, intervenção precoce, tratamento, reabilitação e apoio relacionados com o objetivo de promover a saúde e o bem-estar social dos indivíduos, famílias e comunidades, reduzindo as consequências adversas do abuso de drogas.

A CICAD entende que as políticas de redução de demanda devem ser complementadas por métodos para divulgar informações sobre os riscos associados ao uso de drogas, através do uso de novas tecnologias de informação e pelos meios de comunicação de massa, para informar o público em geral e as várias populações-alvo sobre a prevenção e tratamento disponíveis. Contudo, a redução da demanda exige, de acordo com a situação e magnitude do problema das drogas em cada país, a implementação de uma variedade diferente de programas de prevenção baseados em evidências, visando alvos distintos nas populações, que constituem em conjunto um sistema abrangente.

A instituição coloca que, a partir de uma metodologia e ponto de vista, esses programas devem ser sistemáticos, com objetivos específicos mensuráveis. É necessário investir e dar uma resposta às necessidades específicas dos grupos de risco, incluindo

Em Tese, Florianópolis, v. 10, n. 2, jul./dez., 2013. ISSN: 1806-5023 
crianças, adolescentes e jovens, dentro e fora do sistema de ensino e em outros contextos, territórios e comunidades. Os esforços de prevenção também devem ser dirigidos à população adulta através da família, da comunidade e no local de trabalho. Deve existir, segundo a CICAD, acesso aos sistemas de tratamento que precisam oferecer uma gama de modelos de intervenção terapêutica abrangente (CICAD, 2010).

Devem ser privilegiadas as relações dos governos com instituições acadêmicas e de pesquisa, bem como com organizações não governamentais. Organizações especializadas devem ser reforçadas, a fim de fomentar a pesquisa científica e estudos que gerem evidências sobre os vários aspectos da demanda de drogas, contribuindo assim para a formulação de políticas públicas e um maior conhecimento sobre o assunto. Deve-se fomentar também o constante aperfeiçoamento para a educação e a formação de profissionais, técnicos e outras pessoas envolvidas na implementação de atividades ligadas à redução da demanda.

\section{CONSIDERAÇÕES FINAIS}

Desde a primeira guerra às drogas, o cenário político internacional tem se modificado consideravelmente. Os Estados latino-americanos parecem ter reconhecido as consequências nas diferentes dimensões econômicas, políticas e culturais que o fenômeno causou. A partir da década de 1980, o continente entra em um novo momentum favorável que facilitou a aproximação entre alguns Estados a fim de empreender ações de cooperação internacional. Além da CICAD, criaram-se outras instituições internacionais que colaboram com a implementação de planos para exercer pressão sobre a necessidade de maior comprometimento com as ações delimitadas pela ONU e pela OEA.

É possível observar que os Estados americanos vêm tratando a temática das drogas de forma a constituir uma espécie de regime internacional de combate às drogas do hemisfério ocidental. A dupla ONU e OEA/CICAD, além de tantas outras organizações, solidificam a cada dia uma teia de cooperação e vêm formando um 
arcabouço bastante desenvolvido de legislações, acordos, bases para políticas públicas, mecanismos de fiscalização e controle de eficiência, que vêm ao longo das últimas décadas desenhando a forma de como podemos lidar com as drogas.

O início de uma busca pela multiplicidade nas frentes de batalha contra o fenômeno das drogas mostra que uma mudança de paradigma vem ocorrendo lentamente. A ideia de securitização total, guerra às drogas e combate apenas à oferta vem perdendo espaço paulatinamente para a abordagem da redução da demanda e até mesmo para as políticas de redução de danos e a descriminalização do usuário. $\mathrm{O}$ indivíduo passou a ser o foco da ação e a dependência tratada como uma doença. Um caminho muito grande ainda deve ser trilhado ao equilíbrio no combate ao problema das drogas, e mais pesquisa se faz necessária para avaliar em detalhe os limites e a eficácia das políticas em andamento. Porém, como visto, muitas ações extremamente relevantes estão acontecendo a partir de ambas perspectivas.

\section{REFERÊNCIAS}

CERVO, Amado Luiz. Relações internacionais da América Latina: velhos e novos paradigmas. 2. ed. rev. e atual. São Paulo: Saraiva, 2007.

CICAD. ERCAIAD - Regional School for Anti-drug Intelligence of the American Community. Publicado em: 2012. Disponível em: http://www.cicad.oas.org/Main/Template.asp?File=/reduccion_oferta/ercaiad_eng.asp Acesso em: 16 jun. 2014.

CICAD. Hemispheric Drug Strategy: Plan of action 2011-2014. Publicado em 2010. Disponível em:http://www.cicad.oas.org/Main/AboutCICAD/BasicDocuments/DrugStrategy.pdf. Acesso em: 13 mar. 2014.

CICAD. Resenha: Informação sobre Programas e Projetos (2011) Disponível em:http://www.cicad.oas.org/Main/pubs/CICADbriefing111028-Pt.pdf Acesso em: 28 abr. 2014.

Em Tese, Florianópolis, v. 10, n. 2, jul./dez., 2013. ISSN: 1806-5023 
FERREIRA NETO, Ney J. Estado, narcotráfico e sistema financeiro: algumas aproximações. Florianópolis, 2012. 331 p. Dissertações (Mestrado) - Universidade Federal de Santa Catarina, Centro de Filosofia e Ciências Humanas. Programa de PósGraduação em Sociologia Política.

FRAGA, Paulo César Pontes. A geopolítica das drogas na América Latina. Revista da Faculdade de Serviço Social, v. 19, p. 67-88, set.2007. Disponível em: https://www.epublicacoes.uerj.br/ojs/index.php/revistaempauta/article/viewFile/187/210. Acesso em: 20 mar. 2014

HORWITZ, Betty. The Role of the Inter-American Drug Abuse Control Commission (CICAD): Confronting the Problem of Illegal Drugs in the Americas. Latin American Politics and Society, v. 52, p. 139-165, jun, 2010. Disponível em:http://onlinelibrary.wiley.com/doi/10.1111/j.1548-2456.2010.00084.x/pdf Acesso em: 18 mar. 2014

INSULZA, Miguel José, A Comprehensive Approach to Dealing with the World Drug Problem, Secretary General, Organization of American States (OAS), originally published in the Huffington Post, June 23, 2010, Disponível em: http://www.huffingtonpost.com/jose-miguel-insulza/a-comprehensive-

approach_b_623119.html. Acesso em: 13 mar. 2014

IZQUIERDO, Miguel. La OEA y el combate hemisférico contra las drogas. IN: La OEA hacia el siglo XXI. Revista Mexicana de Política Exterior, n. 54, junio, 1998. Disponível em:http://www.sre.gob.mx/revistadigital/images/stories/numeros/n54/ruizcabanas.pdf.

Acesso em: 18 mar. 2014

KEOHANE, Robert O. After hegemony: cooperation and discord in the world political economy. Oxford: Princeton University Press, 2005.

ORTIZ, Carlos Humberto The War on Drugs is Counterproductive, Once Again, Lecturas de Economía, núm. 71, julio-diciembre, pp. 19-42 Universidad de Antioquia Medellín, Colombia, $2009 . \quad$ Disponível em:http://revinut.udea.edu.co/index.php/lecturasdeeconomia/article/viewFile/4813/4232 Acesso em: 25 mar. 2014

PAGLIARI, Graciela. Segurança regional e política externa brasileira: as relações entre Brasil e América do Sul, 1990-2006. 2009. 281 f., il. Tese (Doutorado em Relações Internacionais). Universidade de Brasília, Brasília, 2009.

Em Tese, Florianópolis, v. 10, n. 2, jul./dez., 2013. ISSN: 1806-5023 
PASSOS, Eduardo; SOUZA, Tadeu. Redução de danos e saúde pública: construções alternativas à política global de guerra às drogas. Psicologia \& Sociedade, v. 23, n.1, p. 154-162, abr. 2011. Disponível em: http://www.scielo.br/pdf/psoc/v23n1/a17v23n1.pdf Acesso em: 22 mar. 2014

PROCOPIO, Argemiro; VAZ, Alcides. O Brasil no contexto do narcotráfico internacional.Revista Brasileira de Política Internacional, Brasília, v. 1, 1997, p. 75122. Disponível em: http://www.scielo.br/scielo.php?script=sci_arttext\&pid=S003473291997000100004. Acesso em: 15 mar. 2014

ROSENBERG, Robin L. The OAS and the Summit of the Americas: Coexistence, or Integration of Forces for Multilateralism?. Latin American Politics and Society, 2001 43: $79-101$.

Disponível em: http://www.jstor.org/discover/10.2307/3177014?uid=37648\&uid=3737664\&uid=37 $647 \&$ uid $=5909624 \&$ uid $=2 \&$ uid $=3 \& u i d=67 \&$ uid $=62 \& \operatorname{sid}=21104627824733$. Acesso em: 30 abr. 2014

SANTANA, Adalberto. A globalização do narcotráfico. Rev. bras. polít. int. Brasília, v. 42, n. 2, Dec. $1999 . \quad$ Disponível em: http://www.scielo.br/scielo.php?script=sci_arttext\&pid=S003473291999000200006\&lng=en\&nrm=iso Acesso em: 22 jun. 2014

SILVA, Luiza Lopes da. A questão das drogas nas relações internacionais: uma perspectiva brasileira. Brasília, DF: Fundação Alexandre de Gusmão, 2013.

TRAGEN, Irving. History of CICAD: How CICAD was founded. CICAD, 2012. Disponível em: http://www.cicad.oas.org/Main/Template.asp?File=/main/aboutcicad/history/start_e ng.asp. Acesso em: 07 jun. 2014.

WRIGHT, Maria da Gloria Miotto et al. A pesquisa sobre o fenômeno das drogas na perspectiva dos estudos multicêntricos na América Latina e Caribe. Rev. Latino-Am. Enfermagem, Ribeirão Preto, v. 17, n. spe, 2009. Disponível em:http://www.scielo.br/scielo.php?script=sci_arttext\&pid=S010411692009000700001\&lng=en\&nrm=iso Acesso em: 15 jun. 2014.

WRIGHT, Maria da Gloria Miotto et al. O papel da cooperação técnica \& financeiro para avançar a profissão de enfermagem na área de redução da demanda na América Latina: desafios e perspectivas. Rev. Latino-Am. Enfermagem, Ribeirão Preto, v. 12, n.

Em Tese, Florianópolis, v. 10, n. 2, jul./dez., 2013. ISSN: 1806-5023 


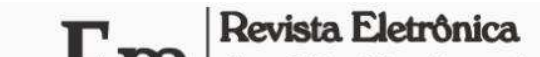

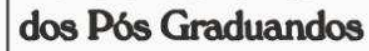

spe, Apr. $2004 . \quad$ Disponível

em: http://www.scielo.br/scielo.php?script=sci_arttext\&pid=S0104-

$\underline{11692004000700002 \& \operatorname{lng}=e n \& n r m=i s o}$ Acesso em: 15 jun. de 2014

WRIGHT, Maria da Gloria Miotto; KHENTI, Akwatu. ES/CICAD-CAMH International Research Capacity-Building Program for Health Related Professionals to Study the Drug Phenomenon in Latin America and the Caribbean. Publicado em 2012. Disponível

em:http://www.cicad.oas.org/reduccion_demanda/educational_development/camh/GWr ight-SAA-Baltimore-ENG-20120326.pdf. Acesso em: 16 jun. 2014.

YOUNG, Oran. A eficácia das instituições internacionais: alguns casos difíceis e algumas variáveis críticas. In: ROSENAU, James e CZEMPIEL, ErnstOtto. Governança sem governo: ordem e transformação na política mundial. Brasília/São Paulo: Editora da UNB/Imprensa Oficial do Estado, 2000.

Em Tese, Florianópolis, v. 10, n. 2, jul./dez., 2013. ISSN: 1806-5023 


\title{
RESUMO
}

O presente artigo analisa o tratamento do fenômeno das drogas na América Latina, discutindo os avanços na criação de um sistema continental de combate às drogas, representado pela Comissão Interamericana para o Controle do Abuso de Drogas (CICAD). A primeira parte do trabalho traça uma retrospectiva da criação da CICAD como iniciativa no surgimento de um arcabouço institucional e legal de tratamento do tema das drogas nas Américas. A segunda parte aborda o processo de consolidação da CICAD como instituição central nesse regime, focada em ultrapassar os métodos tradicionais de enfrentamento do fenômeno. Conclui-se que, ao longo da segunda metade do século $\mathrm{XX}$, os países latino-americanos reagiram diante do fenômeno das drogas e que a criação de um regime interamericano para o tema foi fundamental para $o$ fomento da cooperação regional nessa problemática.

PALAVRAS-CHAVE: Regimes internacionais. Cooperação regional. América Latina. Drogas. Organização dos Estados Americanos.

\begin{abstract}
This article analyses the treatment of the drug phenomenon in Latin America, discussing the advances in the creation of a continental system to combat drugs, represented by the Inter-American Drug Abuse Control Commission (CICAD). The first part traces a retrospective of the work of creation as an initiative of CICAD in the emergence of an institutional and legal framework for addressing the issue of drug phenomenon in the Americas. The second part deals with the process of consolidation of CICAD as a central institution in this regime, focused on overcoming the traditional methods of dealing with the phenomenon. We conclude that, during the second half of the twentieth century, Latin American countries reacted to the drug phenomenon and the creation of an inter-American system was fundamental in developing regional cooperation on this issue.
\end{abstract}

KEYWORDS: International Regimes. Regional cooperation. Latin America. Drugs. Organization of American States.

Em Tese, Florianópolis, v. 10, n. 2, jul./dez., 2013. ISSN: 1806-5023 
Recebido em: 29 de agosto de 2013

Aceito para publicação em: 11 de setembro de 2013

Em Tese, Florianópolis, v. 10, n. 2, jul./dez., 2013. ISSN: 1806-5023 